\title{
BMJ Open A transient peak of infections during onset of rheumatoid arthritis: a 10-year prospective cohort study
}

\author{
Marina I Arleevskaya, ${ }^{1}$ Aida G Gabdoulkhakova, ${ }^{1}$ Yulia V Filina, ${ }^{1}$ \\ Regina R Miftakhova, ${ }^{2}$ Anders Bredberg, ${ }^{2}$ Anatoly P Tsybulkin ${ }^{3}$
}

To cite: Arleevskaya MI, Gabdoulkhakova AG, Filina YV, et al. A transient peak of infections during onset of rheumatoid arthritis: a 10-year prospective cohort study. BMJ Open 2014;4: e005254. doi:10.1136/ bmjopen-2014-005254

- Prepublication history for this paper is available online. To view these files please visit the journal online (http://dx.doi.org/10.1136/ bmjopen-2014-005254).

Received 14 March 2014 Revised 5 August 2014 Accepted 7 August 2014

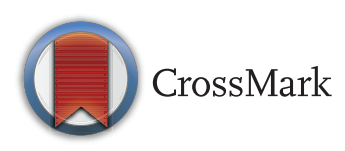

${ }^{1}$ Central Research Laboratory, Kazan State Medical Academy, Kazan, Russia ${ }^{2}$ Department of Laboratory Medicine, Lund University, Skane University Hospital, Malmo, Sweden

${ }^{3}$ Department of the Clinical Laboratory Diagnostic, Kazan State Medical Academy, Kazan, Russia

Correspondence to Dr Marina Arleevskaya, Department of Rheumatology, Kazan State Medical Academy, 11 Mooshtary Street, Kazan 420012, Russia;

marleev@mail.ru

\section{ABSTRACT}

Objectives: The role of infection in rheumatoid arthritis (RA) has not been determined. We aimed to document the infectious burden and some aspects of antibacterial immunity in a large and prospective cohort study of RA patients in the early and late stages of the disease and in their relatives predisposed to RA.

Setting: Clinical and laboratory examination of all individuals enrolled in the study was performed in the Republican Clinical Hospital, Kazan, Russia.

Participants: 376 patients with RA, 251 healthy firstdegree relatives and 227 healthy controls without a family history of autoimmune disease (all females) were examined twice annually over more than 10 years.

Primary and secondary outcome measures: The following parameters were investigated: type, duration and frequency of infections, bacterial colonisation and serum levels of IgG to bacteria, serum levels of total Ig, plasma cytokine levels, granulocyte reactive oxygen species production, lysozyme activity and phagocytosis.

Results: There were no significant differences in infection rate between healthy controls (median 14 days/ year) and RA patients (13). However, infection rates were higher $(p<0.001)$ in healthy relatives $(53)$ and early stage patients (62), which groups also showed heavy bacterial skin colonisation. In contrast, late stage patients had fewer infection days $(12 ; p<0.001)$ than healthy controls, although bacterial colonisation was still heavy. Phagocyte function and antibacterial antibody generation, together with compensatory cytokine production, were observed to be subnormal in the healthy relatives as well as in RA patients.

Conclusions: We observed a marked increase in overall infections at the time of RA onset, and signs of a defective antibacterial defence mechanism, contrasting with fewer infections in the late RA stage. It can be speculated that frequent early infections initiate a compensatory immune hyper-reactivity which reduces the infection load while stimulating the development of $\mathrm{RA}$ in predisposed individuals.

\section{INTRODUCTION}

It has long been hypothesised that infections play a role in the development of rheumatoid arthritis (RA) $\cdot{ }^{1-7}$ However, it remains to

\section{Strengths and limitations of this study}

- Infection rate and bacterial colonisation were increased in relatives and early rheumatoid arthritis (RA).

- In late RA there were fewer infection days and heavy bacterial colonisation.

- There were subnormal innate immune functions and high cytokine levels in the relative and RA groups.

- Frequent infections initiate proinflammatory cytokine hyper-production.

- Compensatory innate immune reaction reduces infections but provokes RA.

be elucidated whether infection is a cause or a consequence (or neither) of the numerous immune aberrations displayed by RA patients. Do infections play a pathogenic role by evoking immune reactions, for example resulting from molecular mimicry with a specific microbe or from repeated exposures to a multitude of foreign agents triggering a wear and tear type of immune defence? ${ }^{8}$

Intrigued by our observations that the leukocytes of RA patients show deficient phagocytosis, ${ }^{9}$ we decided to systematically document infections and some anti-bacterial immune parameters in a prospective large cohort study. Because the early stage of RA is considered to provide a window of opportunity to significantly impede disease progression, ${ }^{10}{ }^{11}$ firstdegree healthy relatives (HR) were included, some of whom developed RA during the study. If exposure to microbes was found to be a significant causative factor, this would have profound implications for our understanding of the pathophysiology of this disease, and how to best design early phase aggressive treatment.

\section{MATERIALS AND METHODS}

\section{Study population}

Most patients in the Tatarstan province in the European part of Russia (population 3.8 
million) who have a clinical history suggesting RA are referred to our specialist hospital. More than $90 \%$ of all women diagnosed with RA at our clinic from 2002 to 2011 were included in the present study. Mean follow-up was 5.4 years. RA was diagnosed by consensus by three rheumatologists using the American Rheumatology Association criteria of 1987, and the EULAR 2010 criteria; for those patients with a diagnosis already when referred to our centre, the time of diagnosis was estimated based on physician records and patient report. Time zero during disease progression was defined as the time when the diagnostic criteria were met. A total of 257 women were studied while in early RA (eRA), defined as $<6$ months of RA duration and 285 women while in late stage RA (laRA), defined as $>3$ years of RA duration (table 1). Some subjects were studied as both HR, eRA and laRA; during the study, 26 HR subjects changed diagnostic group status to eRA, and 185 changed from eRA to laRA, while no healthy control (HC) developed RA. A total of 231 patients were enrolled as eRA and 89 after they had reached laRA status. All patients were asked to invite their first-degree female relatives to participate, and more than half of these relatives accepted, giving a total of $251 \mathrm{HR}$; they showed no symptoms or MRI signs of arthritis, no erythrocyte sedimentation rate (ESR) or C-reactive protein (CRP) elevation (except during infection), and no reactivity of rheumatoid factor or antibody to citrullinated peptides. The HC group comprised 227 women with no chronic disease and no RA among close relatives; these women were identified by a rheumatologist as having no signs of arthritis and negative results in the same laboratory tests as were performed for the HR. Exclusion criteria were some risk factors for infection. ${ }^{7}$ Some $3.6 \%$ were excluded due to strong immunosuppressive therapy, and another $1.3 \%$ because of smoking or habitual alcoholism (by tradition it is uncommon in

\begin{tabular}{|c|c|c|}
\hline $\mathrm{HCs}$ & $\mathrm{HCs}$ & 227 \\
\hline \multirow[t]{2}{*}{ HRs } & HRs total, including & 251 \\
\hline & $\begin{array}{l}\text { HRs moved to the eRA } \\
\text { group }\end{array}$ & 26 \\
\hline \multirow[t]{3}{*}{ eRA } & eRA total, including & 257 \\
\hline & Former HRs & 26 \\
\hline & Enrolled as eRA patients & 231 \\
\hline \multirow[t]{3}{*}{ laRA } & laRA total, including & 274 \\
\hline & Former eRA patients & 185 \\
\hline & $\begin{array}{l}\text { Enrolled as laRA patients } \\
\text { (experience of RA > } 3 \text { years) }\end{array}$ & 89 \\
\hline Intermediate (between & RA patients with $\mathrm{RA}$ & 30 \\
\hline eRA and laRA) & $>6$ months but $<3$ years & \\
\hline Total RA & RA total & 376 \\
\hline \multicolumn{3}{|c|}{$\begin{array}{l}\text { eRA, early RA ( }<0.5 \text { years RA duration); HCs, healthy controls } \\
\text { (women with no RA among close relatives); HRs, healthy } \\
\text { first-degree female relatives of RA patients; laRA, late RA } \\
\text { ( }>3 \text { years RA duration); RA, rheumatoid arthritis. }\end{array}$} \\
\hline
\end{tabular}

this geographical area for a woman to smoke). In addition, $15-20 \%$ of the patients were excluded from participation because of a concomitant chronic disease (mainly diabetes mellitus). All patients were receiving disease-modifying antirheumatic drugs (DMARDs); 35 patients were on infliximab, one on abatacept, two on tocilizumab, and seven on rituximab, and $7 \%$ were on oral prednisolone averaging $10 \mathrm{mg}$ daily.

\section{Study design}

Anamnestic information on infections was collected by a specialist in rheumatology trained in Russia at semiannual in-hospital 2-day visits for most of the HR and the RA patients; for the HC group infection information was from the year preceding enrolment. The study participants were asked about symptoms suggesting infections experienced during the preceding half or whole year. Information from out-clinic documents was sought whenever a general practitioner had been visited. Only those episodes judged by the rheumatologist to truly indicate an infection were scored (there were no formal criteria). In the case of exacerbation of a chronic infection, the diagnosis was established by a specialist in the corresponding medical area. Infections over a 1-year period (the year immediately before assignment as $\mathrm{HC}$, HR or eRA, and the last year as laRA) for each study subject are shown in figure 1. Infection data were collected from all study subjects, but the described tests were performed only for a limited time during the study, with no selection bias other than study time, and thus on only some of the subjects; for bacterial cultures $\mathrm{n}=16-139$, anti-bacterial IgG $\mathrm{n}=16-31$, lysozyme and phagocytosis $\mathrm{n}=31-46$, reactive oxygen species (ROS) production $\mathrm{n}=11-19$, cytokines $\mathrm{n}=14-58$, total Ig levels $\mathrm{n}=56-224$, and $\operatorname{IgE} \mathrm{n}=16-40$. Written informed consent was obtained from all subjects. The study was approved by the ethics committee of the Kazan State Medical Academy, Kazan, Russia (Permit no. 1/2002).

\section{Experimental procedures}

Bacterial cultures were established from skin (lower volar arm) cotton swabs and from urine and faeces samples, in the Bacteriology Laboratory, Republic Hospital Number 3, Kazan, following routine procedures established by Russian federal authorities. For quantitation, the skin swab material or $1 \mathrm{~g}$ faeces was suspended in 1 or $10 \mathrm{~mL}$, respectively, phosphate-buffered neutral $\mathrm{pH}$ saline; then $10 \mu \mathrm{L}$ of this suspension or of urine was streaked onto a Petri dish. Samples were obtained on several occasions, but only one result for each sample type (with the most complete sample set and from the most recent date) per individual is presented in this manuscript. Bacterial samples and blood for immunological investigation were taken only in the absence of clinical signs of infection.

Phagocytosis of ${ }^{14} \mathrm{C}$-labelled Staphylococcus aureus and lysozyme activity were measured as described earlier. ${ }^{12}$ ROS were analysed by luminol-dependent 

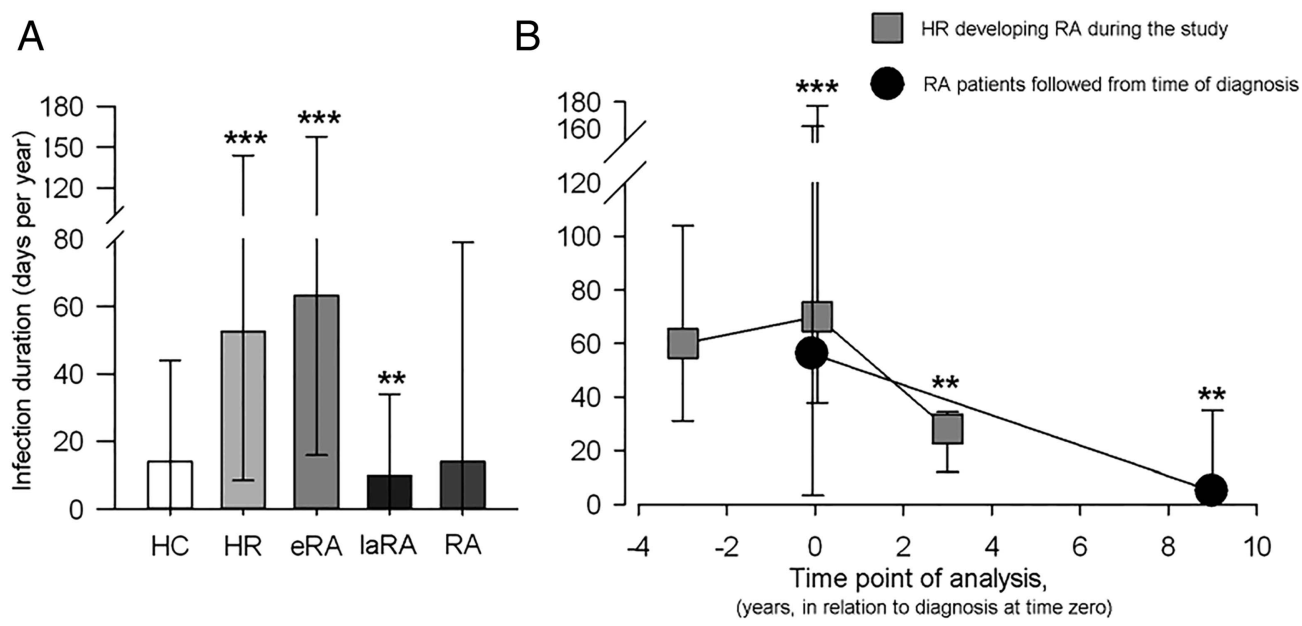

Figure 1 The number of days with an infection during the 1-year period preceding either the first examination ( $\mathrm{HC}$ and $\mathrm{HR})$, arthritis onset (eRA) or the last examination (laRA). (A) All subjects; (B) HR developing RA and followed to the late stage (a box symbol) and RA patients followed from time of diagnosis (a circle symbol). ${ }^{* *} p<0.01,{ }^{* \star} \mathrm{p}<0.001$, as compared with $\mathrm{HC}$ (A, Mann-Whitney test) and as compared with the data in the preceding time point of analysis (B, Wilcoxon test). The median is shown, and whiskers denote $5 \%$ and $99 \%$ percentiles. eRA, early RA patients ( $<0.5$ years RA duration); HC, healthy controls (women with no RA among close relatives); HR, healthy first-degree female relatives of RA patients; laRA, late RA patients ( $>3$ years RA duration); RA, all rheumatoid arthritis patients.

chemiluminescence real time registration using a chemiluminometer designed by Dr Santalov, Pushchino, Russia, with opsonised zymosan (Sigma, USA; final concentration $0.25 \mathrm{mg} / \mathrm{mL}$ ) as stimulant. Serum IgG to $S$. aureus, ${ }^{13}$ Staphylococcus epidermidis and Escherichia coli was determined with ELISA (Navina, Russia). Plasma levels of tumour necrosis factor $\alpha$ (TNF- $\alpha)$, interleukin-1 $\beta$ (IL-1 $\beta$ ) and interleukin-6 (IL-6) were measured by ELISA (Vector-Best Test Systems, Russia), and interferon $\gamma$ (IFN- $\gamma$ ) by ELISA (BioLegend, USA). Serum IgG, IgM and IgA total levels were studied using a turbidometric method (Human Diagnostics, Germany), and IgE by ELISA (R\&D, USA).

\section{Statistical analysis}

The sign criterion, Student $\mathrm{t}$ test for independent samples, the Mann-Whitney test, Wilcoxon test, $\chi^{2}$ criterion and regression analysis were used. The Pearson criterion was used if case normal distribution was evident. The Spearman rank order correlation test and multiple regression analysis were used for analysis of association between infections and age.

\section{RESULTS}

\section{Number of days with an infection experienced during a} 1-year period

The infection results for the 1-year period preceding either the first examination (HC and HR), arthritis onset (eRA) or the last examination (laRA) are presented in figure 1A. There was no significant difference in the median number of infection days between $\mathrm{HC}$ (14) and all RA patients together (13). Higher figures were noted for HR $(53, \quad \mathrm{p}<0.001)$ and eRA
(62, $\mathrm{p}<0.001)$. The laRA patients had fewer infection days $(12, \mathrm{p}<0.01)$ than HC (14).

Infection results recorded at different time points for those HR subjects $(n=26)$ who developed RA during the study, and for a subset of RA patients $(\mathrm{n}=185)$ followed for a relatively long period starting at the time of diagnosis, are presented in figure 1B. Among this HR subgroup, infection duration was lower at the first examination (4 years before being diagnosed with RA) (60 days, left in figure 1B) as compared with the year preceding diagnosis $(70$, middle in figure $1 \mathrm{~B} ; \mathrm{p}<0.001)$. At the last follow-up of 11 of these 26 individuals, at 2.8 years after diagnosis, there was a decrease to 28 days (right in figure $1 \mathrm{~B} ; \mathrm{p}<0.01$, as compared with the two earlier time points). Among the 185 RA patients followed from time of diagnosis, a decrease from 56 to 5 days was noted at 8.4 years after diagnosis $(\mathrm{p}<0.01)$ (figure 1B). There was no significant correlation between the age of the studied subjects and infection duration (results not shown).

\section{Infection types}

We also scored infection types (table 2). There was no infection in $12.4 \%$ of $\mathrm{HC}, 4.0 \%$ of HR ( $\mathrm{p}<0.05), 2.0 \%$ of eRA $(\mathrm{p}<0.01)$ or $28.3 \%$ of laRA $(\mathrm{p}<0.01)$. The most frequent type of infection in all groups was influenza-like symptoms, with no differences between $\mathrm{HC}, \mathrm{HR}$ and eRA; however the laRA group showed lower values. Symptoms typical for herpes simplex were more frequent, and each episode was longer, for HR and eRA; for laRA the result was similar to HC, but laRA had fewer episodes than eRA. Higher percentages of HR and eRA than HC had upper respiratory and urinary tract infections; again, laRA displayed lower rates. For many of the types of infection with a probable bacterial origin, 
Table 2 Incidence and duration of some infection types during a 1-year period $\dagger$

\begin{tabular}{|c|c|c|c|c|}
\hline Infection type & HC $(n=227)$ & HR $(n=251)$ & eRA $(n=257)$ & IaRA $(n=274)$ \\
\hline No infection & 12.4 & $4^{*}$ & $2^{\star \star}$ & $28.3^{\star \star} \# \#$ \\
\hline Influenza-like symptoms & $51.3(7)$ & $56.8(7)$ & $52.4(7)$ & 42.6\# (7) \\
\hline Herpes simplex blisters & $22.1(7)$ & $39^{\star *}\left(10^{\star}\right)$ & $33.3^{\star *}\left(10^{\star}\right)$ & 17.4\#\# (7.9) \\
\hline Upper respiratory tractł & $32.0(8.4)$ & $51.0^{\star * \star}(10)$ & $48.8^{\star \star \star}\left(12.1^{\star}\right)$ & $22.5^{\star \star} \# \#(7.7)$ \\
\hline Chronic otitis, exacerbation & 0 & $2.8(14)$ & $3.6^{\star *}(14)$ & $0(0)$ \\
\hline Chronic bronchitis, exacerbation & $1.3(30)$ & $4^{*}(30)$ & $6.3^{\star \star}(30)$ & $1.9 \#(21)$ \\
\hline Pneumonia & 0 & $0.4(30)$ & $2.4^{\star \star}(21)$ & $0.4(14)$ \\
\hline Furunculosis, no fever & $1.8(10.5)$ & $9.6^{\star *}(14)$ & $11.9^{\star \star}(14)$ & $0.4 \# \#(10)$ \\
\hline Urinary tract infection & $2.2(10)$ & $5^{\star}(10)$ & $6.7^{\star \star}(14)$ & $0.8 \# \#(7 \# \#)$ \\
\hline High fever of uncertain origin & 0 & $3.2^{\star \star}(22)$ & $2^{*}(26)$ & $0 \#(0)$ \\
\hline Hospitalised infections & 0 & $0.4 \# \#(30)$ & $7.1^{* \star}(20)$ & $0.4 \# \#(14)$ \\
\hline
\end{tabular}

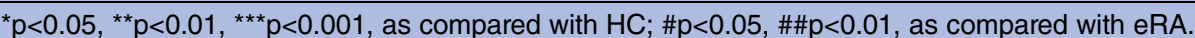

†ncidence as \% of the individuals in the group with the particular infection (case duration as days, mean) is shown.

łncluding acute tonsillitis, otitis and sinusitis.

eRA, early RA patients ( $<0.5$ years RA duration); HC, healthy controls (women with no RA among close relatives); HR, healthy first-degree

female relatives of RA patients; laRA, late RA patients ( $>3$ years RA duration); RA, rheumatoid arthritis.

HR and eRA showed increase rates, while laRA had a tendency to lower rates (as compared with HR, eRA as well as HC). This can be exemplified by significant differences for acute sinusitis episodes (forming part of the upper respiratory tract data), with this type of infection affecting $2.7 \%$ of all $\mathrm{HC}, 4.8 \%$ of $\mathrm{HR}, 6.0 \%$ of eRA and $0.8 \%$ of laRA.

\section{Bacterial colonisation}

Samples for bacterial culture were taken from faeces, urine and skin at a time when the subjects showed no signs of infection (figure 2A). A high bacterial count was defined arbitrarily as $>10^{5}$ colony-forming units (CFU) per $\mathrm{mL}$ of a suspended skin swab, as $>10^{5} \mathrm{CFU}$ per $\mathrm{mL}$ urine and as $>4 \times 10^{8} \mathrm{CFU}$ per $\mathrm{g}$ of suspended faeces. For all three bacterial species and three sample types, high CFU values were more frequent among HR, eRA and laRA as compared with HC. As an example, a high count of $S$. aureus was found in 1 of $23(4 \%) \mathrm{HC}$ skin samples, in 13 of $38(34 \%)$ HR samples, in 16 of 45 $(36 \%)$ eRA samples and in 17 of 75 (23\%) laRA samples $(p<0.001$ for HR and eRA, and $p<0.01$ for laRA, as compared with $\mathrm{HC}$ ). For laRA, the $E$. coli and $S$. aureus CFU tended to be lower than for $\mathrm{HR}$ and $\mathrm{eRA}$,
Figure 2 (A) Fraction of subjects showing heavy bacterial colonisation; (B) serum levels of IgG to Escherichia coli, Staphylococcus epidermidis and Staphylococcus aureus. A high bacterial colony-forming unit (CFU) count was defined arbitrarily (see text). In B, the subjects were separated into two subgroups depending on whether there was a high CFU count ('Positives') for any of the cultured samples. ${ }^{* *} p<0.01$, as compared with $\mathrm{HC}$; $\# p<0.01$, \#\#p<0.001, as compared with eRA. The median and $5 \%$ and $99 \%$ percentiles are shown. eRA, early RA patients ( $<0.5$ years $R A$ duration); $\mathrm{HC}$, healthy controls (women with no RA among close relatives); HR, healthy first-degree female relatives of RA patients; laRA, late RA patients ( $>3$ years RA duration); RA, rheumatoid arthritis.
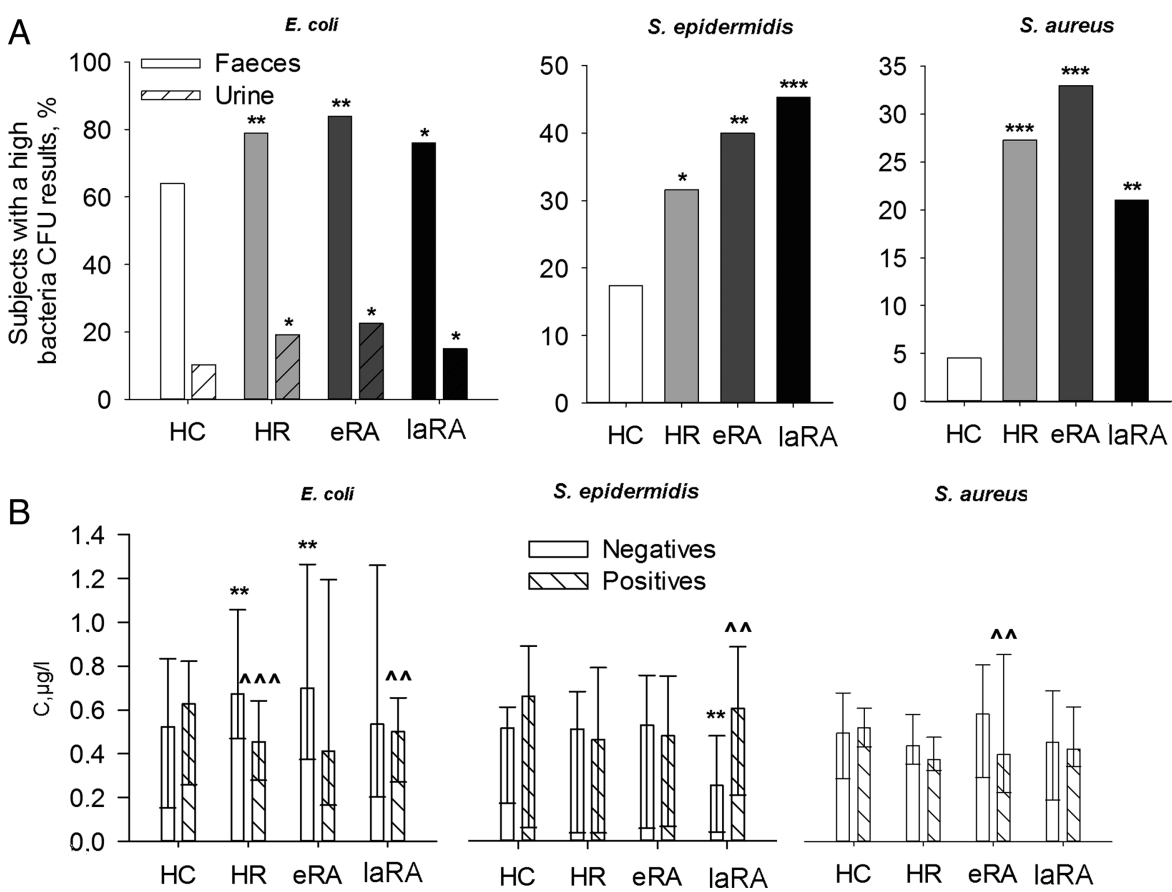
Figure 3 Serum levels of total $\lg A$, $\lg M$ and $\lg G(A)$ and $\lg E(B)$. ${ }^{* *} p<0.05,{ }^{* * *} p<0.01$, as compared with $\mathrm{HC}$. The median and $5 \%$ and 99\% percentiles are shown. eRA, early $R A$ patients $(<0.5$ years $R A$ duration); $\mathrm{HC}$, healthy controls (women with no RA among close relatives); HR, healthy first-degree female relatives of $\mathrm{RA}$ patients; laRA, late $R A$ patients $(>3$ years RA duration); RA, rheumatoid arthritis.
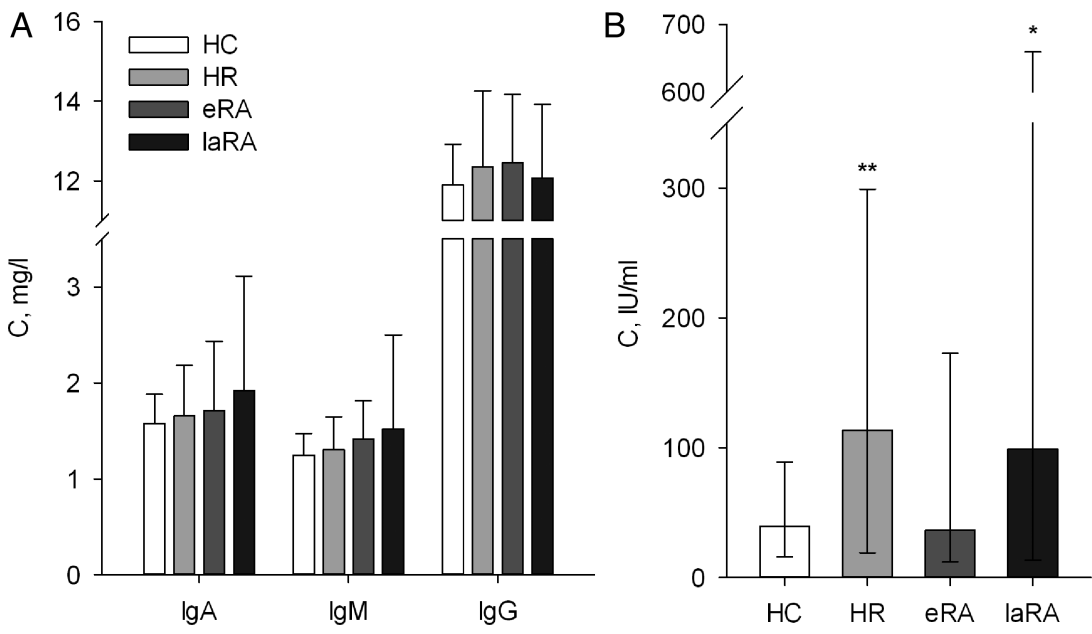

whereas CFU for the less pathogenic commensal S. epidermidis tended to be higher.

\section{Serum IgG to $E$. coli, $S$. aureus and $S$. epidermidis, and total Ig levels}

There was no significant difference between the groups in serum levels of IgG to E. coli, S. aureus or S. epidermidis (results not shown). However, if the subjects were separated into those with and without a high CFU result (as shown in figure 2A), a pattern could be discerned (figure 2B). Among the HC, the anti-E. coli and anti-S. aureus IgG levels were higher in subjects with more colonisation, whereas among HR and eRA the opposite was noted, and laRA showed an intermediate result with no apparent difference between the two CFU groups. This pattern was evident also for anti-S. epidermidis among HC, HR and eRA, but the laRA patients showed the same result as the HC, that is, a higher IgG level in those with heavy bacterial colonisation. There was no difference in serum levels of total IgG, IgM or IgA between the subject groups $(n=56-224)$ (figure $3 A)$. In a smaller subject subset $(\mathrm{n}=16-40)$, the serum total $\mathrm{IgE}$ level was approximately twofold elevated in $\operatorname{HR}(p<0.01)$ and laRA $(p<0.05)$, but with no deviation in eRA as compared with $\mathrm{HC}$ (figure 3B).

\section{Plasma cytokine levels}

In plasma obtained from subjects without signs of infection, levels of TNF- $\alpha$, IL- 6 and IFN- $\gamma$ (not significant only with IFN- $\gamma$ in eRA) were increased in HR, eRA and laRA as compared with HC (figure 4). A high level of IL-1 $\beta$ was detected in HR and less so in laRA. For TNF- $\alpha$ and IL-6, with monocytes considered to be a rich source, there was a tendency for eRA to show a lower concentration than HR and laRA. For IFN- $\gamma$, originating mainly from $\mathrm{T}$ cells, there was a similar pattern.

\section{Phagocyte function}

Granulocytes from HR, eRA and laRA displayed a normal level of spontaneous (figure $5 \mathrm{~A}$ ) and stimulated (figure 5B) generation of ROS; however, after stimulation with opsonised zymosan the time needed to reach peak ROS production was significantly prolonged in HR, eRA and laRA (figure 5C). The antibacterial activity of lysozyme secreted by granulocytes, as well as granulocyte phagocytosis of $S$. aureus, were markedly reduced in both laRA and HR (figure 5D-E); eRA samples were not available for analysis for these two immune
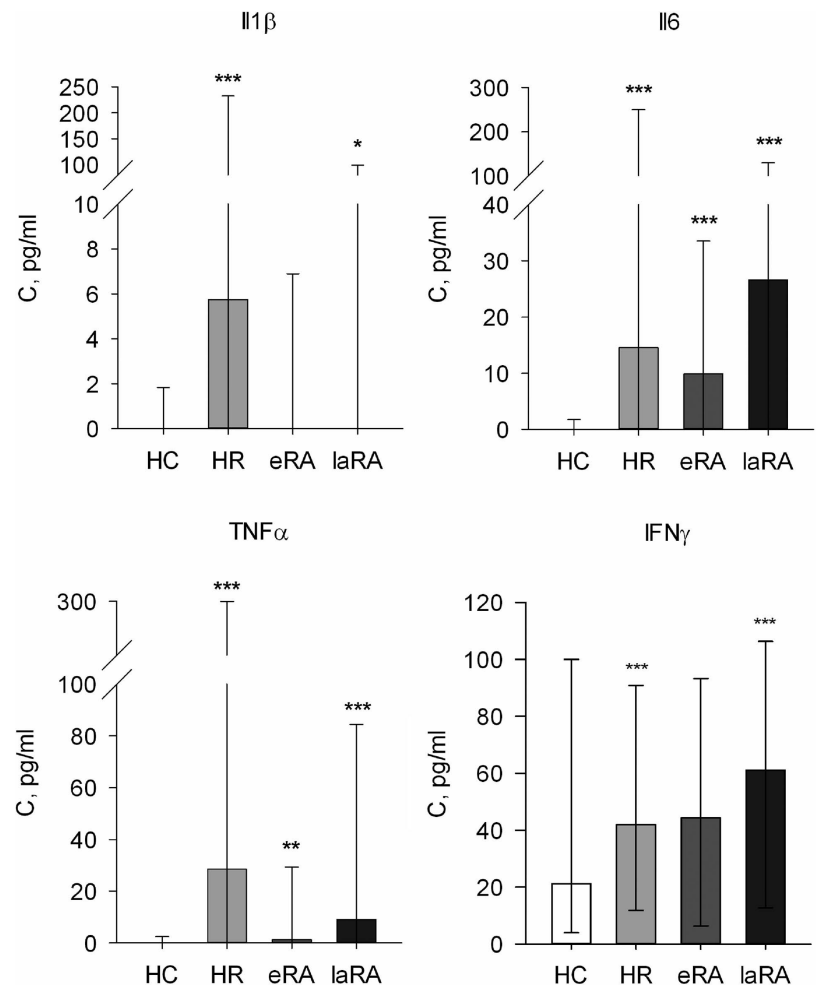

Figure 4 Plasma cytokine levels. ${ }^{*} p<0.05,{ }^{* *} p<0.01$, ${ }^{* * *} \mathrm{p}<0.001$, as compared with $\mathrm{HC}$. The median and $5 \%$ and $99 \%$ percentiles are shown. eRA, early RA patients (<0.5 years $\mathrm{RA}$ duration); $\mathrm{HC}$, healthy controls (women with no $\mathrm{RA}$ among close relatives); HR, healthy first-degree female relatives of $R A$ patients; laRA, late $R A$ patients ( $>3$ years $R A$ duration); RA, rheumatoid arthritis. parameters. 


\section{DISCUSSION}

The quantity of overall infections was higher in the HR as compared with the HC group. It was further elevated in eRA, but lower in late laRA stage, even significantly lower than in the HC. The summary effect for the entire RA group was a slightly elevated (not significantly) infection quantity. Accordingly, there was an increase in infections in HR as they developed RA $(n=26)$, and a decrease among RA patients after they transitioned from eRA to laRA $(n=135)$. This strong correlation between infections and disease duration may have contributed to the previously published conflicting data on infection quantity in RA; for example, the relatively few hospitalised infections reported for methotrexate-treated patients may reflect a long disease duration. ${ }^{14}$

Because this study was designed to examine the possible role of exposure to microbial antigens in a broad sense, we examined some aspects of the commensal bacterial flora, and the scoring of infections was not limited to objectively verifiable and severe types, such as septic arthritis. We were encouraged by previous observations that self-reporting by patients can serve as a valuable indicator of common infections. ${ }^{15}{ }^{16}$ At the same time we are aware of the impact which confounding factors can have on the scoring of most types of infections. For example, non-microbial inflammation may mimic infection. Drug usage may also have a confounding effect; consumption of antibiotics with activities other than anti-bacterial might have an impact on infection score. ${ }^{17}$
Furthermore, the more anti-inflammatory medication administered, the less severe the symptoms indicating infection. In fact, we did observe more infections among the eRA group (in whom infections during the 1-year period preceding diagnosis were scored) who were on less drug therapy compared to the laRA patients, who had far fewer infections and all of whom were prescribed DMARD. Nevertheless, we find it highly unlikely that our finding of fewer infections in late stage patients is due to DMARD usage. First, the observed extent of infection reduction (from 62 days in eRA to 12 days in laRA, figure 1A) is too large to be due to drug masking of signs of infection; second, the highly significantly increased infection load seen at time of diagnosis in the HR subjects developing RA (figure 1B) cannot be attributed to a decrease in DMARD intake. In conclusion, our data suggest true differences in microbial flora and infection quantity.

The high frequency of infections was accompanied by a high level of bacterial colonisation in both HR and eRA. This situation was different in laRA, where a marked reduction in infections was coupled with persistent strong colonisation. Some anti-bacterial defences were observed to function at a clearly subnormal level in both the early and late stages of RA, and also in the HR. These were neutrophil lysozyme activity, which was in accordance with a report of a markedly reduced (6.6-fold) expression level of the lysozyme gene in RA patient blood mononuclear cells, ${ }^{18}$ and phagocytosis of
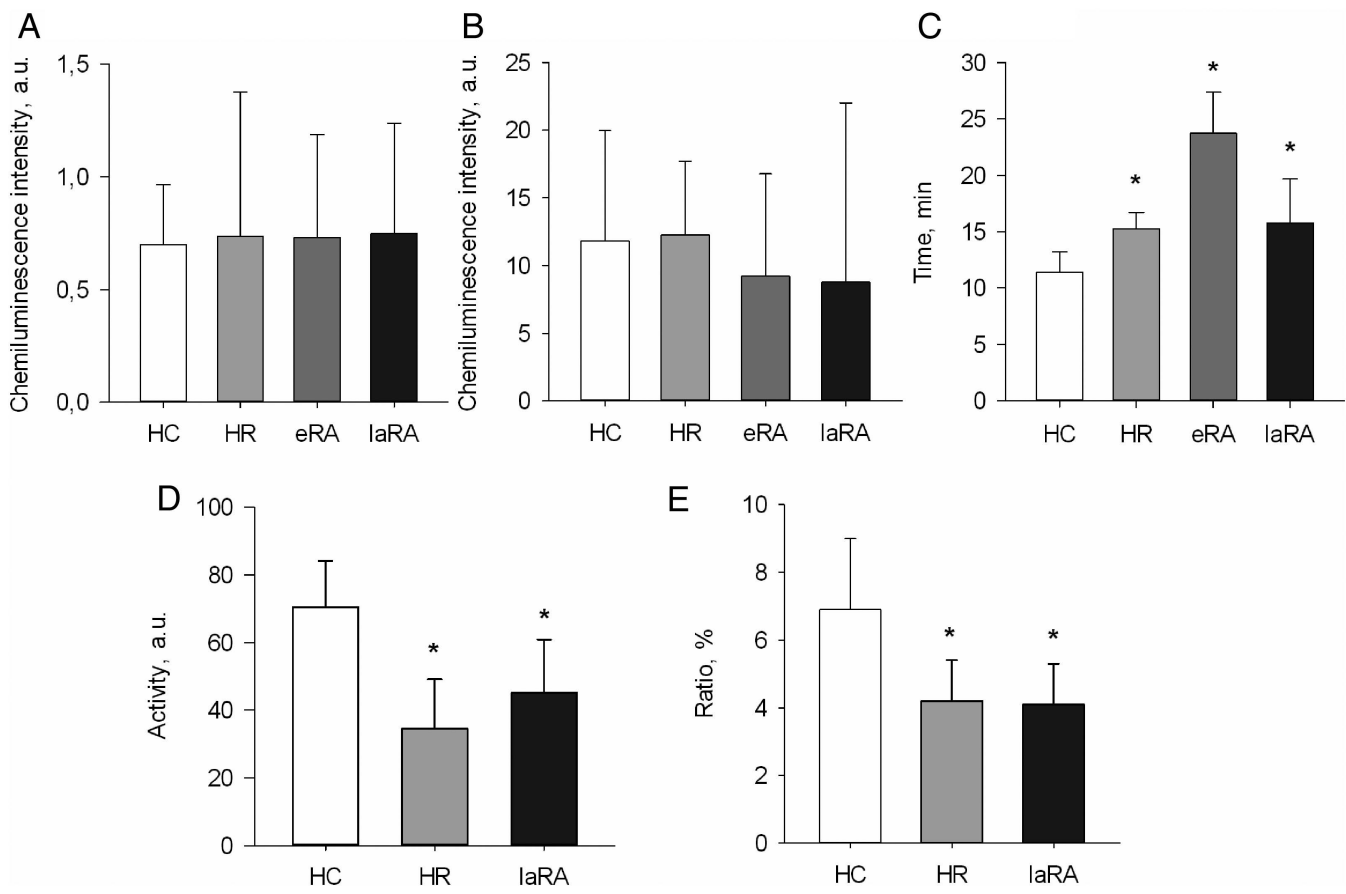

Figure 5 Granulocyte phagocytosis functions: spontaneous (A) and stimulated (B) ROS production, time to reach peak ROS production (C), lysozyme activity (D) and phagocytosis of Staphylococcus aureus (E). ${ }^{*} \mathrm{p}<0.05$ as compared with $\mathrm{HC}$. The median and $5 \%$ and $99 \%$ percentiles (A,B) and mean and SE (C,D) are shown. eRA, early RA patients ( $<0.5$ years RA duration); $\mathrm{HC}$, healthy controls (women with no RA among close relatives); HR, healthy first-degree female relatives of RA patients; laRA, late RA patients ( $>3$ years RA duration); RA, rheumatoid arthritis; ROS, reactive oxygen species. 
S. aureus by granulocytes. Another major anti-bacterial defence mechanism is production of ROS by granulocytes; we noted signs of reduced capacity in HR and RA patients, in line with findings that ROS protects against $\mathrm{RA}$ in the $\mathrm{Ncfl}^{\mathrm{DA}}$ rat model, ${ }^{19}$ and low antioxidant activity in RA patients. ${ }^{20}$

We acknowledge that it remains to be elucidated whether infections, and exposure to more or less immunogenic colonising bacteria, act as 'driver' or 'passenger' phenomena during RA development. Hypothetically, at least two scenarios can be postulated: (1) frequent infectious episodes and RA could be two causally independent consequences of an immune system disturbance; and (2) recurrent infections contribute to RA development. Since the correlation between RA activity and infection quantity in eRA is opposite to that in laRA, it seems that the second scenario is the most likely.

Our collected findings suggest the following model for the pathogenesis of RA. Some anti-bacterial defence mechanisms, operating at a subnormal level during all stages of RA, result in an RA-predisposing exposure to microbial antigens in the shape of commensals and infections. A set of compensatory immune reactions follow. An increase in other defence mechanisms eventually succeeds in curbing the high level of infections, while exerting less influence on colonisation. The model is supported by evidence indicating that monocytes and macrophages, ${ }^{21}$ as well as other cytokine-producing cell types, ${ }^{22}$ are key players in RA, and by more recent reports of non-specific and sustained immunostimulation during RA development. ${ }^{13} 2425$ The composition of the commensal bacterial flora, and gut microbiota manipulation, is known to influence inflammatory diseases and not least RA. ${ }^{23-29}$ Data from genome-wide association studies provide evidence that numerous factors beyond those analysed by us influence the development and progression of RA. ${ }^{30}{ }^{31}$ Notably, a high infection quantity was revealed by us in the great majority of, but not all, HR and eRA patients. So, microbial exposure might be a very important but not unique provoking factor.

In conclusion, our observations may prompt further studies on the clinical value of controlling infections and of manipulation of our commensal microbiota.

Contributors MIA, APT and AB: conceived and designed the study; MIA: conducted clinical examinations and selected the study subjects; MIA, AGG, RRM and YVF: performed the experiments; all authors: analysed the data; $M I A$ and $A B$ : wrote the paper.

Funding This study was supported by grants from the Russian Foundation for Basic Research (00-04-48224 and 04-09-97053), the Swedish Institute (01474/2007) and the Alfred Osterlund Foundation.

Competing interests None.

Patient consent Obtained

Ethics approval All aspects of the study were approved by the ethics committee of Kazan State Medical University.

Provenance and peer review Not commissioned; externally peer reviewed.

Data sharing statement No additional data are available.
Open Access This is an Open Access article distributed in accordance with the Creative Commons Attribution Non Commercial (CC BY-NC 4.0) license, which permits others to distribute, remix, adapt, build upon this work noncommercially, and license their derivative works on different terms, provided the original work is properly cited and the use is non-commercial. See: http:// creativecommons.org/licenses/by-nc/4.0/

\section{REFERENCES}

1. Kay A. Infection in rheumatoid arthritis. Lancet 1968;290:152

2. Leirisalo-Repi M. Early arthritis and infection. Curr Opin Rheum 2005;17:433-9.

3. Ogrendik M, Hakgruder A, Keser N. Treatment of rheumatoid arthritis with ornidazole. A randomized, double-blind, placebo-controlled study. Rheumatology 2006;45:636-7.

4. Vanderbroucke JP, Kaaks R, Valkenburg HA, et al. Frequency of infections among rheumatoid arthritis patients, before and after disease onset. Arthritis Rheum 1987;30:810-13.

5. Doran MF, Crowson CS, Pond GR, et al. Frequency of infection in patients with rheumatoid arthritis compared with controls. Arthritis Rheum 2002;46:2287-93.

6. Vinogradiva Y, Hippisley-Coc J, Coupland C. Identification of new risk factors for pneumonia: population-based case-control study. $\mathrm{Br} \mathrm{J}$ Gen Pract 2009;59:e329-338.

7. Söderlin MK, Bergsten U, Svensson B, et al. BARFOT study group. Patient-related events preceding the onset of rheumatoid arthritis: possible clues to aetiology. Musculoskeletal Care 2011;9:25-31.

8. Murakami M, Okuyama $\mathrm{Y}$, Ogura $\mathrm{H}$, et al. Local microbleeding facilitates IL-6- and II-17-dependent arthritis in the absence of tissue antigen recognition by activated T cells. J Exp Med 2011;208:103-14.

9. Arleevskaya MI, Gabdoulkhakova AG, Filina JV, et al. Mononuclear phagocytes in rheumatoid arthritis patients and their relativesfamily similarity. Open Rheumatol $J$ 2011;5:36-44.

10. Boers M. Editorial. Understanding the window of opportunity concept in early rheumatoid arthritis. Arthritis Rheum 2003;48:1771-4.

11. Maclnnes IB, O'Dell JR. State-of-the-art: rheumatoid arthritis. Ann Rheum Dis 2010;69:1898-906.

12. Arleevskaya MI, Zabotin Al, Khaliullina DG, et al. Absorption and digestion of phagocytized objects by mononuclear phagocytes during rheumatoid arthritis. Bull Exp Biol Med 2004;2:150-51.

13. Abramson C, Bergdoll MS, Wheat LJ. Cumitech 22 Immunoserology of staphylococcal disease //Coordinating ed., Abramson C. Washington, DC: American Society for Microbiology, 1987.

14. Smitten AL, Choi HK, Hochberg MC, et al. The risk of hospitalized infection in patients with rheumatoid arthritis. J Rheumatol 2008;35:387-93.

15. Patkar CJR, Greenberg JA, Solomon DH. Validity of physician-reported hospitalized infections in a US arthritis registry. Rheumatol 2009;48:1269-72.

16. Simard JF, Stoll ML, Shadick NA, et al. Validity of self-report of infections in a longitudinal cohort of patients with rheumatoid arthritis differs by source of report and infection severity. $J$ Clin Epidemiol 2010;63:1358-62.

17. O'Doell JR, Elliott JR, Mallek JA, et al. Treatment of early seropositive rheumatoid arthritis: doxycycline plus methotrexate versus methotrexate alone. Arthritis Rheum 2006;54:621-7

18. Edwards CJ, Feldman JL, Beech J, et al. Molecular profiling of peripheral blood mononuclear cells from patients with rheumatoid arthritis. Mol Med 2007;13:40-58

19. Hultqvist $M$, Olofsson $P$, Gelderman $K A$, et al. A new arthritis therapy with oxidative burst inducers. PLoS Med 2006;3:e348.

20. Sarban S, Kocyigit A, Yazar M, et al. Plasma total antioxidant capacity, lipid peroxidation, and erythrocyte antioxidant enzyme activities in patients with rheumatoid arthritis and osteoarthritis. Clin Biochem 2007;38:981-6.

21. Szekanecz Z, Koch AE. Macrophages and their products in rheumatoid arthritis. Curr Opin Rheum 2007;19:289-95.

22. Yeo L, Toellner KM, Salmon M, et al. Cytokine mRNA profiling identifies $B$ cells as major source of RANKL in rheumatoid arthritis. Ann Rheum Dis 2011;70:2022-8.

23. Hill DA, Siracusa MC, Abt MC, et al. Commensal bacterial-derived signals regulate basophil hematopoiesis and allergic inflammation. Nat Med 2012;18:538-46. 
24. Scheinecker C, Smolen JS. From the gut to the joint. Year in review. Nat Rev Rheumatol 2011;7:73-5.

25. Chodick G, Amital H, Shalem Y, et al. Persistence with statins and onset of rheumatoid arthritis: a population-based cohort study. PLoS Med 2010;7:e1000336.

26. Jarchum I, Pamer E. Regulation of innate and adaptive immunity by the commensal microbiota. Curr Opin Immunol 2011;23:353-60.

27. Clemente JC, Ursell LK, Wegener Parfrey L, et al. The impact of the gut microbiota on human health: an integrative view. Cell 2012;148:1258-70.
28. Sanford JA, Gallo RL. Functions of the skin microbiota in health and disease. Semin Immunol 2013;25:370-7.

29. Scher JU, Sczesnak A, Longman RS, et al. Expansion of intestinal Prevotella copri correlates with enhanced susceptibility to arthritis. eLife 2013;2:e01202.

30. Orozco $G$, Barton $A$. Update on the genetic risk factors for rheumatoid arthritis. Expert Rev Clin Immunol 2010;6:61-75.

31. Kochi Y, Suzuki A, Yamada R, et al. Ethnogenetic heterogeneity of rheumatoid arthritis-implications for pathogenesis. Nat Rev Rheum 2010;5:290-5. 